\title{
ELEMENTOS PARA A COMPREENSÃO DA TEORIA DOS PRECEDENTES EM TEMPOS PANDEMIA: DISTINGUISHING E PROSPECÇÃO ${ }^{1}$
}

\section{ELEMENTS FOR THE COMPREHENSION OF THE THEORY OF PRECEDENTES ON PANDEMIC TIMES: DISTINGUISHING AND PROSPECTION}

William Soares Pugliese

Pós-doutor pela UFRGS. Doutor e Mestre pelo PPGD-

UFPR. Professor do Programa de Pós-graduação em

Direito da Unibrasil (Curitiba/PR). Gastforscher no Max-Planck-Institut für ausländisches öffentliches Recht und Völkerrecht. Coordenador da Especialização de Direito Processual Civil da Academia Brasileira de Direito Constitucional (ABDConst). Advogado. Curitiba/PR. E-mail: william@pxadvogados.com.br

RESUMO: O presente artigo procura responder como as relações jurídicas afetadas pela pandemia da COVID-19 se vinculam aos precedentes disponíveis no ordenamento jurídico brasileiro. Para tanto, parte-se de uma investigação da compreensão teórica do problema, no sentido de que a pandemia transforma casos fáceis em difíceis. Em seguida, o artigo demonstra que a diferença entre os casos comuns e os pandêmicos é fática, de modo que a técnica a ser empregada para a não aplicação de precedentes é a do distinguishing. Ao final, propõe-se que os tribunais fundamentem cuidadosamente suas decisões para evitar o uso indevido desses precedentes.

PALAVRAS-CHAVE: Pandemia. Precedentes. Fundamentação.

ABSTRACT: This article seeks to answer how the legal relationships affected by the COVID-19 pandemic are linked to the precedents available in the Brazilian legal system. To do so, it starts with an investigation of the theoretical understanding of the problem, in

\footnotetext{
1 Artigo recebido em 05/06/2020 e aprovado em 18/11/2020.
} 
the sense that the pandemic transforms easy cases into hard ones. Then, the article demonstrates that the difference between common and pandemic cases is factual, so that the technique to be used for not applying precedents is the distinguishing. In the end, it is proposed that the courts carefully substantiate their decisions to avoid misuse of these precedents.

KEY WORDS: Pandemic. Precedents. Reasoning.

\section{Introdução}

O período da pandemia oriunda da COVID-19 tem sido considerado um momento sem precedentes, no mais amplo sentido da expressão. A quarentena, em especial, vem impedindo que uma série de pessoas desempenhem atividades econômicas, mudou os hábitos da população e forçou, à sua moda, as pessoas a ficarem forçosamente em casa. Tão notório é o fato e suas repercussões que não se mostra necessário ir além para demonstrar este ponto. O que importa, aqui, é que a pandemia impõe reflexões por parte da doutrina jurídica e decisões por parte da magistratura. Em outras palavras, pensar a pandemia, em termos jurídicos, é pensar como a doutrina e a jurisprudência podem contribuir para a solução de problemas decorrentes da disseminação do coronavírus.

Sabe-se, por outro lado, que as decisões judiciais dependem, atualmente, de fundamentação com base em precedentes. Como decorrência de propostas teóricas e de alterações legislativas, a teoria dos precedentes foi incorporada ao Direito brasileiro e, dentre outros efeitos, o Código de Processo Civil de 2015 exige que as decisões judiciais demonstrem a similaridade entre o caso previamente julgado e o em exame e que identifiquem os fundamentos determinantes aplicáveis. Ou seja, a lei brasileira instituiu uma espécie de stare decisis no processo civil. Sem ingressar, por ora, no debate acadêmico sobre os efeitos dos precedentes, é razoável afirmar que, nos termos da legislação, os precedentes devem ser ao menos considerados para a decisão a ser proferida.

Estabelecida as duas premissas (a pandemia da COVID-19 e a teoria dos precedentes em vigor no país), anuncia-se o problema a ser enfrentado no presente artigo. Se a pandemia alterou as relações jurídicas, como justificar eventual não aplicação de 
precedente que, em condições normais, seria pertinente ao caso em análise? Por exemplo: não há dúvidas de que as hipóteses de restrição de liberdade, no país, são restritas à pena por crimes e como medida executiva indireta para o cumprimento de prestação de alimentos; no entanto, no período da quarentena, há decisões que determinam o isolamento de famílias dentro da casa. ${ }^{2}$ Certamente, o magistrado conhece a jurisprudência sobre o tema e nem por isso deixou de determinar uma medida de restrição de liberdade. Por que, no período da quarentena, decisões como esta são razoáveis?

Para desenvolver o tema, o primeiro tópico a ser enfrentado diz respeito a algumas particularidades dos fatos e das relações jurídicas que foram impactadas pelos efeitos da quarentena. Em síntese, o argumento central, aqui, será o de que a pandemia transformou casos fáceis em difíceis, na ótica da Teoria do Direito. Consequentemente, há um número maior de elementos envolvidos nos casos que influenciarão as decisões.

O segundo ponto a ser considerado diz respeito aos elementos específicos dos precedentes pertinentes ao tema. Essencialmente, serão expostos os pontos essenciais para a identificação dos elementos fáticos da ratio decidendi, denominados de fatos materiais, e a exposição da técnica precisa da distinção (distinguishing) como instrumento adequado para a justificação de decisões que se afastem dos precedentes existentes.

$\mathrm{O}$ resultado dos dois primeiros itens é a produção de precedentes próprios para o período da pandemia, marcados pelos fatos específicos decorrentes do momento vivido e pelas provas necessariamente produzidas nos autos. Deste modo, o terceiro ponto pretende responder a um questionamento decorrente dos anteriores: qual a utilidade e a força dos precedentes formados durante a pandemia? $\mathrm{O}$ artigo sustenta que os precedentes da pandemia integrarão um conjunto próprio de decisões específicas para períodos de exceção e que os tribunais deverão tomar os devidos cuidados com este aspecto ao fundamentar os acórdãos. Para tanto, faz-se breve incursão ao julgamento do caso Re A (conjoined twins), proferido pela Court of Appeal da Inglaterra e País de Gales. As cautelas adotadas por aquele tribunal oferecem ensinamentos importantes para a redação de decisões de casos excepcionais e para demarcar os limites dos "precedentes pandêmicos".

2 CARDOSO, Rômulo. COVID 19: Juiz de Marechal Cândido Rondon determina isolamento de sete pessoas de uma família. Curitiba: Amapar, 2020. Disponível em: <https://bit.ly/2RpDked>. Acesso em: 23 abr. 2020. 


\section{A pandemia e os casos difíceis}

O objetivo deste item é compreender a causa do problema aqui examinado: por que os casos relacionados à pandemia demandam decisões complexas? A resposta reside no aspecto de que os argumentos tecidos pelos advogados e os pedidos formulados ao judiciário, no período pandêmico, fogem do padrão e das previsões legais. Assim, um contrato de aluguel, cuja disciplina já está mais do que consolidada no ordenamento jurídico brasileiro, torna-se objeto de intensas discussões jurídicas, tais como pedidos de postergação de pagamento e suspensão de ordens de despejo. Pedidos como esses não são permitidos pela legislação, pelo que normalmente são afastados de plano pelos magistrados ou sequer seriam formulados pelos advogados. No entanto, as circunstâncias atuais favorecem o desenvolvimento de novos argumentos, como a impossibilidade de despejo por conta da necessidade de reclusão na residência. Ou seja, o risco à saúde do locatário, em uma situação de despejo, gera uma causa de derrotabilidade ${ }^{3}$ implícita da norma e permite ao magistrado a tomada de uma decisão distinta.

O Direito Privado oferece outros exemplos, inclusive algumas hipóteses em que o próprio legislador reflete a respeito de Regime Jurídico Emergencial e Transitório para o período da pandemia. Trata-se do Projeto de Lei 1.179/2020, que para além do tema o despejo trata dos prazos prescricionais e decadenciais, das relações de consumo, veda a prisão civil do devedor de alimentos (salvo a prisão domiciliar), dentre outros. Verifica-se que este projeto de lei propõe o que se afirmou acima ao dispor expressamente sobre hipóteses de excepcionalidade (explícitas) do direito positivo. A quarentena alça situações jurídicas normais ao limite daquilo que é previsto pela legislação e, por isso, torna casos fáceis em casos difíceis. É o que se passa a expor com maior cautela.

A concepção de "caso difícil" é relativamente recente no âmbito da Teoria do Direito. As primeiras definições desta figura datam da segunda metade do século XX, especialmente nos escritos de juristas influenciados por H. L. A. Hart. ${ }^{4}$ Destes, destacam-

\footnotetext{
${ }^{3}$ Sobre o tema, ver SERBENA, Cesar Antonio. Teoria da derrotabilidade: pressupostos teóricos e aplicações. Curitiba: Juruá, 2012; VASCONCELLOS, Fernando Andreoni. Hermenêutica jurídica e derrotabilidade. Curitiba: Juruá, 2010.

${ }^{4}$ HART, Herbert L. A. The concept of Law. 3.ed. Oxford: Oxford University Press, 2012. A edição original data de 1961.
} 
se dois para a compreensão do tema nos limites deste artigo: Neil MacCormick e Ronald Dworkin.

Não é surpresa que Dworkin trabalhou a definição de casos difíceis. Em sua primeira obra monográfica ${ }^{5}$, a noção de casos difíceis ocupa um papel relevante no desenvolvimento de seus argumentos. O propósito central do autor em Taking Rights Seriously era desenvolver uma crítica ao positivismo jurídico, principalmente o positivismo de Hart. Nessa crítica, o autor sustenta que o direito não seria um sistema de regras em sentido estrito, ou seja, "um padrão de avaliação de condutas que segue uma gramática lógica de tipo 'tudo ou nada"'. 6 A gramática da linguagem jurídica é mais complexa e se constitui de princípios, que "envolvem algum tipo de ponderação e/ou balanceamento que somente é realizado por meio de justificação argumentativa".7

Evidentemente, essa diferença na natureza das normas jurídicas produz resultados diferentes quando examinadas sob a luz de casos. Os casos fáceis, neste sentido, seriam aqueles que possuem uma regra aplicável que determina o resultado do julgamento, na lógica do tudo ou nada. ${ }^{8}$ Já os casos difíceis são aqueles para os quais não há uma regra identificável para sua solução. ${ }^{9}$ Ou seja, para Dworkin, casos difíceis são casos que não são resolvidos pela aplicação objetiva de uma regra.

Em Taking Rights Seriously, Dworkin não tinha a intenção de desenvolver com maior profundidade a noção de caso difícil. $\mathrm{O}$ fato de que há casos que não podem ser resolvidos por uma regra era suficiente para que seu argumento central pudesse prosseguir. É justamente por isso que a obra de MacCormick também deve ser considerada, neste momento. Ao oferecer uma resposta hartiana à crítica de Dworkin, MacCormick ${ }^{10}$ buscou classificar os casos difíceis e demonstrar como o positivismo era capaz de solucionar esses

\footnotetext{
${ }^{5}$ DWORKIN, Ronald. Taking Rights Seriously. Cambridge: Harvard University Press, 1977.

${ }^{6}$ MACEDO JR., Ronaldo Porto. Do xadrez à cortesia: Dworkin e a teoria do direito contemporânea. São Paulo: Saraiva, 2013. p.162.

${ }^{7}$ MACEDO JR., Ronaldo Porto. Do xadrez à cortesia: Dworkin e a teoria do direito contemporânea. São Paulo: Saraiva, 2013. p.162..

${ }^{8}$ Uma das passagens de Dworkin que permitem essa afirmação é a seguinte: "This theory holds that a legal obligation exists whe (and only when)na established rule of Law imposes such an obligation." (DWORKIN, Ronald. Is Law a system of rules? In: The Philosophy of Law. Oxford: Oxford University Press, 1977. p.64).

$9 " B u t$ if the case at hand is a hard case, when no settled rule dictates a decision either way, it might seem that a proper decision could be generated by either policy or principle." (DWORKIN, Ronald. Taking Rights Seriously. Cambridge: Harvard University Press, 1977. p.83).

10MacCORMICK, Neil. Argumentação jurídica e teoria do direito. São Paulo: Martins Fontes, 2006.
} 
casos. ${ }^{11}$ Para ele, casos fáceis admitem justificações por dedução, enquanto os casos difíceis demandam justificativas de segunda ordem.

O Direito, para o professor escocês, gira em torno de uma espécie particular de argumentação prática, cuja principal função é justificar escolhas e decisões. ${ }^{12}$ Mais do que isso, o Direito é composto por um conjunto de premissas normativas que auxiliam o processo e que permite, até mesmo, que algumas decisões sejam tomadas a partir de um raciocínio exclusivamente dedutivo. Casos que admitem decisões como essas são chamados casos fáceis. Nas palavras do autor, "às vezes é possível demonstrar em termos conclusivos que uma determinada decisão é legalmente justificada por meio de um argumento puramente dedutivo". ${ }^{13}$ Os casos fáceis, portanto, nada mais seriam que situações jurídicas que admitem justificações por dedução. Assim, casos fáceis são hipóteses em que os fatos estão devidamente estabelecidos e o direito aplicável é identificado sem qualquer dúvida.

Há, porém, casos em que as soluções legais não podem ser deduzidas, mas ainda assim demandam uma resposta pelo Judiciário. MacCormick apresenta uma divisão de quatro espécies de casos que não admitem soluções por simples dedução. São os problemas de interpretação, de pertinência, de prova e de qualificação. Para os fins desta exposição, os problemas de prova e de qualificação demandam maior aprofundamento. ${ }^{14}$

Os problemas de prova são ligados ao estabelecimento da premissa menor e a dificuldade de identificar o que de fato ocorreu em determinado caso. Como explica Atienza, este problema não surge da necessidade apenas de se identificar a verdade, mas também superar um teste de coerência: "o fato de que todas as peças da história parecem se ajustar bem (e que não se tenha infringido nenhuma regra processual de avaliação da prova)". O problema da prova está especialmente ligado aos casos em que se alega a pandemia de COVID-19 porque, apesar da própria pandemia ser um fato notório, esta

\footnotetext{
${ }^{11}$ Refere-se, aqui, ao chamado primeiro MacCormick, positivista filiado a Hart. A passagem do autor para o chamado pós-positivismo ocorreu apenas no século XXI. Sobre o desenvolvimento do pensamento do autor, ver: KOZICKI, Katya; PUGLIESE, William S. Direito, Estado e Razão Prática: a teoria do direito de Neil MacCormick. In: TORRANO, Bruno; OMMATI, José Emílio Medauar (Org.). O positivismo jurídico no século XXI. Rio de Janeiro: Lumen Juris, 2018. p.145-181.

${ }^{12}$ ATIENZA, Manuel. As razões do direito. 2.ed. Rio de Janeiro: Forense, 2014. p.134.

${ }^{13}$ MacCORMICK, Neil. Argumentação jurídica e teoria do direito. São Paulo: Martins Fontes, 2006. p.23-24.

${ }^{14}$ As demais espécies de problemas, que não são pertinentes para este texto, podem ser consultadas no já citado KOZICKI, Katya; PUGLIESE, William S. Direito, Estado e Razão Prática: a teoria do direito de Neil
} 
mesma afirmação não pode ser feita para as consequências materiais da quarentena sobre casos específicos. Ou seja, deve haver prova de que determinada empresa sofreu impactos econômicos em razão do coronavírus, de que um alimentante teve diminuição de seus rendimentos ${ }^{15}$, ou de qualquer outro fato relacionado aos efeitos da disseminação da doença e de sua prevenção.

Nesta linha, uma das causas pelas quais a pandemia torna os casos difíceis é porque surgem problemas de prova. Isto ocorre porque as narrativas apresentadas aos juízos tornam-se mais complexas e demandam maior atenção dos magistrados para uma avaliação de coerência interna. Esta, porém, não é a razão principal.

A ordem de problema que parece mais comum quando se examinam os casos surgidos no curso da pandemia são os problemas de qualificação ${ }^{16}$, ou de classificação. ${ }^{17}$ Este problema também decorre de uma análise dos fatos, mas a complexidade da análise surge no momento em que estes fatos precisam ser interpretados e subsumidos a uma norma. Ele ocorre se "fatos secundários são suscitados quando não há dúvidas sobre a existência de determinados fatos primários (que se consideram provados), mas o que se discute é se eles integram ou não um caso que possa ser subsumido no caso concreto da norma". ${ }^{18}$

Um problema de qualificação surge, assim, no momento em que há dúvida com relação à relevância de fatos extraordinários incidentes sobre uma relação jurídica comum. As medidas de prevenção contra o coronavírus são exemplo claro dessas situações. Por exemplo, não há dúvida de que a visitação é um direito dos filhos em relação aos pais, com fulcro no artigo 1.632, do Código Civil. No entanto, durante o período de quarentena, é razoável sustentar que a visitação física seja substituída por contatos virtuais ou telefonemas, especialmente se houver risco de contaminação entre as partes. A questão que

MacCormick. In: TORRANO, Bruno; OMMATI, José Emílio Medauar (Org.). O positivismo jurídico no século XXI. Rio de Janeiro: Lumen Juris, 2018.

${ }^{15}$ XAVIER, Marília Pedroso. Como evitar oportunismos nas revisionais de alimentos na pandemia. Consultor Jurídico, São Paulo, 2020. Disponível em: <https://www.conjur.com.br/2020-abr-15/direito-civilatual-evitar-oportunismos-revisionais-alimentos>. Acesso em: 17 de maio de 2020.

${ }^{16} \mathrm{Na}$ tradução de MacCORMICK, Neil. Argumentação jurídica e teoria do direito. São Paulo: Martins Fontes, 2006. p.47-65.

${ }^{17} \mathrm{Na}$ apresentação sobre o tema de ATIENZA, Manuel. As razões do direito. 2.ed. Rio de Janeiro: Forense, 2014. p.141.

${ }^{18}$ ATIENZA, Manuel. As razões do direito. 2.ed. Rio de Janeiro: Forense, 2014. p.141-142. 
se apresenta, nesta hipótese, é justamente a influência da COVID-19 em uma relação familiar.

O mesmo ocorre em outras situações. O fundamento para um locatário não pagar o aluguel raramente é acolhido em juízo. A pandemia, porém, configura uma questão fática que pode afetar a relação inadimplida. É o caso, novamente, de um problema de qualificação, pois a complexidade reside na avaliação da pandemia como fato secundário e seus efeitos sobre a relação jurídica comum. É este elemento de qualificação, ou classificação, que parece ser o ponto em comum nas causas surgidas após a pandemia. Dos contratos de locação à proibição de circulação de pessoas em locais públicos, o que há de comum é a ameaça da COVID-19 e seus já consolidados efeitos sobre as situações e relações jurídicas tradicionais.

Isto significa que há razões reais para a complexidade dos julgamentos a serem proferidos neste momento. Os pedidos são outros, os fundamentos são inéditos e as decisões, necessariamente, serão diferentes do material que há disponível na jurisprudência brasileira. Tem-se, aqui, um indicativo do que será sustentado no próximo item: não se tem precedentes adequados para os casos surgidos na pandemia. Mas, isto não significa que não se deva falar na teoria dos precedentes. É o que se passa a expor.

\section{Precedentes, fatos materiais e distinções}

A teoria dos precedentes foi paulatinamente incorporada ao Direito brasileiro na última década. Primeiro, por parte da doutrina ${ }^{19}$, que buscava uma solução para a falta de isonomia nas decisões. Mais tarde, a figura dos precedentes foi adotada pelo legislador, fazendo expressa menção ao instituto no Código de Processo Civil de 2015. Os precedentes têm como função principal a implementação da ideia do stare decisis, ou seja, o respeito ao que já se decidiu e a preservação dos entendimentos previamente firmados. No entanto, o período atual de pandemia da COVID-19 pode ser considerado um momento histórico sem precedentes e, também, um momento sem precedentes judiciais. Vale dizer que, salvo algumas recentes decisões proferidas por tribunais, datadas de março de 2020

\footnotetext{
${ }^{19}$ CRUZ E TUCCI, José Rogério. Precedente judicial como fonte do direito. São Paulo: Revista dos Tribunais, 2004; MARINONI, Luiz Guilherme. Precedentes obrigatórios. São Paulo: Revista dos Tribunais, 2010;
} 
em diante, não há um conjunto de decisões aplicáveis aos casos difíceis. Muito menos há que se falar em precedentes dos tribunais superiores, preenchendo os requisitos qualitativo, material e funcional, nos termos propostos por Daniel Mitidiero. ${ }^{20}$

$\mathrm{O}$ que se tem a disposição é um grande número de precedentes que orientam a decisão de casos em condições ditas, para os fins deste trabalho, "normais". Estas decisões deverão ser consideradas, mas não necessariamente seguidas. Explica-se. Não há dúvida de que os precedentes oferecem parâmetros de interpretação para o direito positivo. Mais, se houver precedente aplicável a um caso, este deverá, no mínimo, ser considerado na fundamentação do magistrado, nos termos do art. $489, \S 1^{\circ}$, do Código de Processo Civil. Isto significa que a pandemia não gera uma tabula rasa para a jurisprudência. Ao contrário, o conjunto de decisões e precedentes não pode ser negado e deve ser mantido estável, íntegro e coerente, como preceitua o art. 926, também do CPC.

O que precisa ser compreendido são os limites entre os precedentes de um período sem quarentena e os casos novos formados durante os riscos da COVID-19. O elemento chave para esta distinção se encontra na compreensão da delimitação fática da ratio decidendi. Este desenvolvimento recorre a uma lição seminal da teoria dos precedentes, qual seja, o clássico texto de Arthur Goodhart sobre a determinação da ratio. ${ }^{21}$ Neste artigo, o então professor de Oxford apresentou quatro regras para a identificação dos fundamentos determinantes da decisão.

Das quatro regras essenciais para a identificação da ratio, duas (a terceira e a quarta) são absolutamente essenciais para este texto. A terceira pode ser assim enunciada: o juiz é quem escolhe quais fatos são importantes para a resolução do caso. Isso quer dizer que nem todos os fatos apresentados em juízo são levados em consideração para a tomada da decisão. Quem interpreta o precedente deve analisar como o juiz observou os fatos e as provas para então avaliar qual foi a decisão tomada.

A quarta regra complementa e auxilia na compreensão da anterior. Existem dois tipos de fatos: os materiais e os imateriais. Os fatos materiais são aqueles considerados relevantes para a tomada da decisão; já os imateriais são fatos que não contribuem para a

BARBOZA, Estefânia Maria de Queiroz. Precedentes judiciais e segurança jurídica: fundamentos e possibilidades para a jurisdição constitucional brasileira. São Paulo: Saraiva, 2014.

${ }^{20}$ MITIDIERO, Daniel. Precedentes: da persuasão à vinculação. São Paulo: Revista dos Tribunais, 2016.

${ }^{21}$ GOODHART, Arthur L. Determining the ratio decidendi of a case. Yale Law Journal, Yale, v.40, n.2, p.161-183, dez. 1930. 
decisão ter sido tomada em determinado sentido. Alguns fatos são tipicamente imateriais, pois estão ligados à imparcialidade do Judiciário, tais como pessoa, lugar, tempo e valor. No entanto, todo fato também pode ser material, desde que seja assim considerado na fundamentação.

Deste modo, mesmo que exista erro na interpretação dos fatos pelo magistrado, o exame da decisão ao se buscar a ratio decidendi deve partir da premissa de que a solução jurídica proposta tem como quadro fático o conjunto de fatos materiais da forma como descritos pelo juiz. São essas duas as regras centrais que permitiram a Goodhart enunciar, inclusive, o seu conceito de ratio: a regra jurídica definida pelo juiz para decidir o caso da forma como ele o observou, ou seja, de acordo com os fatos considerados materiais.

Como exposto acima, as duas regras relacionadas aos fatos para a identificação da ratio são imprescindíveis para a compreensão do sistema de precedentes durante a pandemia. Recordando o que se afirmou no item anterior, os casos se tornam difíceis durante a quarentena provocada pela COVID-19 porque é necessário qualificar um quadro fático complexo e inédito nas categorias já existentes do Direito. A proposta de Goodhart oferece um critério para a identificação do quadro fático e permite a delimitação dessa narrativa. E é exatamente este o ponto que torna os precedentes pandêmicos diferentes dos precedentes "normais": entre eles, há diferenças entre os fatos materiais identificados pelo julgador. Esta observação traz ao palco outros dois institutos da teoria dos precedentes: o stare decisis e o distinguishing.

Por stare decisis, refere-se à teoria que determina aos juízes respeitem os precedentes estabelecidos por decisões anteriores, seja de tribunais hierarquicamente superiores, seja do próprio órgão que compõem. Para Eisenberg, esta proposta decorre do ideal de estabilidade, visto como forma de se garantir um tratamento isonômico a todo o jurisdicionado e de legitimar as decisões tomadas pelo Poder Judiciário,22 Também é possível acrescer à noção primordial de estabilidade a ideia de universalidade, segundo a qual as questões devem ser decididas de acordo com regras aplicáveis não só a um caso particular, mas também a todos os casos semelhantes. ${ }^{23} \mathrm{~A}$ universalidade determina que o Judiciário julgue e fundamente suas decisões por meio da articulação e aplicação de regras

\footnotetext{
${ }^{22}$ EISENBERG, Melvin Aron. The nature of the common law. Cambridge: Harvard University Press, 1988.
} p.47. 
que possam ser aplicadas no futuro a todas as pessoas na mesma situação dos litigantes. ${ }^{24}$ Assim, o stare decisis está diretamente ligado a outro tradicional brocado, qual seja, treat like cases alike. Em tradução literal, é "tratar casos iguais de forma igual".

Esta breve incursão ao tema do stare decisis não tem o objetivo de desviar o tema aqui analisado. ${ }^{25}$ Ao contrário, quer-se demonstrar que os casos surgidos no período da quarentena terão semelhança a outros, já julgados. Justamente por isso, a primeira opção do magistrado pode ser a de aplicar o precedente disponível para a solução mais eficaz e universalizante. Quanto a isso, deve-se registrar que a opção é possível, desde que o magistrado esteja convencido de que a pandemia não produziu qualquer efeito relevante sobre a relação jurídica em análise. Ou seja, ao decidir, o juiz afasta a COVID-19 como fato material de suas razões de decidir. Ao assim agir, a decisão deverá utilizar os precedentes disponíveis para preservar o stare decisis.

Há pelo menos duas situações que justificarão a aplicação do stare decisis. A primeira, mais simples, diz respeito aos casos que se encontram pendentes de julgamento e que tratam de situações jurídicas desenvolvidas em momento anterior à pandemia. Pode parecer desnecessário dizer, mas esta é a primeira situação em que a pandemia não deve ser considerada ao se julgar. A segunda hipótese que afasta o tratamento dos casos como específicos da pandemia é a constatação, pelo órgão julgador, de que o caso não foi suficientemente afetado pela COVID-19 a ponto de justificar um tratamento diferenciado. Ou seja, a decisão não nega a quarentena, mas não a considera juridicamente relevante para a situação jurídica apreciada. Para estas duas hipóteses, cabe seguir o stare decisis e aplicar os precedentes para que casos iguais sejam tratados de forma igual.

Resta avaliar a saída para julgamento dos casos efetivamente afetados pela pandemia. Aqui, a solução está no distinguishing, ou distinção. ${ }^{26}$ Esta técnica propõe que, se o caso a ser decidido é diferente do precedente, o juiz não precisa decidir no mesmo

\footnotetext{
${ }^{23}$ EISENBERG, Melvin Aron. The nature of the common law. Cambridge: Harvard University Press, 1988. p.5.

${ }^{24}$ EISENBERG, Melvin Aron. The nature of the common law. Cambridge: Harvard University Press, 1988. p.9. Sobre a universalidade, ver também a definição de MacCORMICK, Neil. Retórica e o estado de direito. São Paulo: Elsevier, 2008. p.128-29.

${ }^{25}$ Para uma descrição completa sobre o stare decisis, ver MERRYMAN, John Henry; PÉREZ-PERDOMO, Rogelio. A tradição da Civil Law: uma introdução aos sistemas jurídicos da Europa e da América Latina. Tradução de Cássio Casagrande. Porto Alegre: Sergio Antonio Fabris, 2009.

26 Uma explicação completa sobre o tema pode ser consultada em BUSTAMANTE. Thomas da Rosa. Teoria do procedente judicial. São Paulo: Noesses, 2012.
} 
sentido. Ou melhor, não há um precedente a ser seguido, exatamente porque o caso é outro. Para que seja realizado o distinguishing impõe-se a descrição do caso com especial destaque para os elementos fáticos que afastam a incidência do precedente. $\mathrm{O}$ magistrado deverá redigir a decisão conferindo especial destaque para os fatos materiais que identificou na análise dos autos e que o levam a distinguir a situação contemporânea e a examinada pelo precedente.

O distinguishing é o instituto que permitirá o afastamento dos precedentes "normais" dos casos impactados pela COVID-19. É por meio dessa técnica que os advogados fundamentarão a possibilidade de tratamento diferenciado do caso, mesmo com a existência de precedentes apontando para outro sentido. É pelo uso das distinções que os magistrados estabelecerão os pontos fáticos que tornam casos surgidos durante a pandemia diferentes dos anteriores.

Para que o distinguishing seja realizado de forma adequada, impõe-se que sejam destacados os fatos materiais assim considerados para a tomada da decisão. Ao negar um pedido fundado de despejo, por exemplo, poderá o juiz destacar o contexto de isolamento social e o risco ao qual exporá o réu caso este seja removido de sua residência. Estas observações conferem materialidade à pandemia como fato e permitem a distinção do caso contemporâneo dos precedentes. Essa mesma técnica servirá como base para a identificação de qualquer situação jurídica materialmente marcada pela COVID-19, por suas medidas de prevenção ou até mesmo pelos efeitos econômicos que desencadeou. Portanto, é essencial que as petições desses casos sejam marcadas por argumentação jurídica e produção probatória acerca dos efeitos particulares da pandemia. Consequentemente, as decisões poderão fazer uso desses argumentos e provas para conferir destaque aos fatos materiais que tornam a decisão típica do momento pandêmico.

Com isso, tem-se por demonstrado os limites da teoria dos precedentes e as razões pelas quais é possível derivar dos precedentes disponíveis para decidir casos durante a pandemia de COVID-19. O que ainda precisa ser considerado é a responsabilidade do órgão julgador ao tomar a decisão para o caso marcado pela pandemia. Afinal, as decisões proferidas neste período terão potencial para se tornarem precedentes e, se não forem tomadas as devidas precauções, haverá grande dificuldade de se diferenciar precedentes "pandêmicos" dos demais. 


\section{Formação de precedentes para a pandemia}

No item acima, sustentou-se que a partir do distinguishing e do estabelecimento de fatos materiais típicos do período da pandemia será possível formar novos precedentes. $\mathrm{O}$ que demanda atenção, agora, é o cuidado com a clara identificação dos já referidos precedentes pandêmicos. Trata-se, em outras palavras, de um olhar para o futuro. A pergunta que se procura responder é em que medida um precedente formado no período da quarentena pode ser empregado para outros casos, quando a pandemia for controlada.

Quando o magistrado ou a Corte se encontra diante de um caso sem precedentes a tarefa de decidir adquire maior responsabilidade. Suas decisões não mais produzem efeitos somente em relação às partes, mas a todo o jurisdicionado. O juiz, ao decidir, não está simplesmente resolvendo um caso com a possibilidade de torná-lo imutável para as partes. Sua decisão produz efeitos muito mais amplos e é relevante para todo o jurisdicionado, já que poderá ser invocada como precedente pelas partes e deverá ser observada pelos demais julgadores. ${ }^{27}$ Nesse sentido, aliás, quanto mais alta for a posição hierárquica ocupada por um tribunal, em relação à possibilidade de revisão das decisões, maior será a relevância da decisão.

Assim, a responsabilidade dos magistrados para decidir questões novas e relevantes para a sociedade passa a ser maior. Os resultados dessa constatação são bastante benéficos para o Judiciário. Em primeiro lugar, garante-se a imparcialidade do julgador de forma objetiva. Explica-se: se o juiz tem consciência de que sua decisão será utilizada para a solução de todos os casos semelhantes ao que ele tem em mãos, será compelido a desconsiderar qualquer questão particular que, eventualmente, pudesse motivá-lo a decidir em favor de uma das partes. ${ }^{28}$ Além disso, a responsabilidade do magistrado favorece a produção de decisões com fundamentos mais profundos e com a discussão de todas as Application of Judicial Decisions. Harvard Journal of Law \& Public Policy, Cambridge, v.26, p.812-876, 2003.

${ }^{28}$ Nesta mesma linha, Neil MacCormick sustenta a universalidade da fundamentação das decisões. Ver MacCORMICK, Neil. Retórica e o estado de direito. São Paulo: Elsevier, 2008. 
razões alegadas pelas partes. Mais do que isso, o juiz pode se dedicar ao exame e à exposição dos fatos que o levaram a adotar um determinado posicionamento.

Ao se deparar com um caso sem precedentes, o órgão julgador tende, portanto, a decidir de forma mais cuidadosa e com uma preocupação prospectiva. Vale dizer, em síntese, que a existência de um caso difícil, sem regra ou precedente disponível, deve despertar no magistrado ou no colegiado a responsabilidade extraordinária de formação do precedente.

No entanto, seria insuficiente concluir que, diante de todo o exposto, deveria o julgador considerar as circunstâncias do caso concreto. Seguindo o papel esperado da doutrina ${ }^{29}$, é possível estabelecer alguns parâmetros para esses precedentes. Em primeiro lugar, há de se considerar que a pandemia gera uma situação de escassez. São raras as empresas que vêm apresentando crescimento econômico durante a propagação da COVID19. Ao contrário, o cenário é de pessimismo e de derrocada econômica. Ou seja, a presunção, aqui, é a de que a maioria dos casos levados ao Poder Judiciário durante o momento vivenciado seja relacionado à impossibilidades de cumprimento de obrigações e ônus. Outro tipo de pedido que pode ser previsto tem relação com o impedimento de circulação de pessoas em prol da sociedade.

Tome-se como exemplo da primeria hipótese um importador de produtos chineses que não conseguiu pagar tributos em abril e maio de 2020. Este importador deverá, em um primeiro momento, demonstrar qual a relação entre o não pagamento de tributos e a pandemia - alegando, possivelmente, o não recebimento dos produtos importados e a redução de seus ganhos. Diante desses fatos, poderá o julgador decidir que, pelos fatos materiais do caso, é possível prorrogar o pagamento de impostos por um determinado período.

O conjunto de decisões a respeito do momento pandêmico formará, em um primeiro momento, a jurisprudência sobre o tema. Em seguida, com o exame dos casos pelos tribunais superiores, haverá a formação de precedentes válidos para todo o território nacional. É possível que esse desenvolvimento seja concluído apenas após o fim da pandemia. No entanto, os precedentes formados serão válidos para a solução de outros casos decorrentes da COVID-19 ainda pendentes de julgamento e, na pior das hipóteses, 
para outro momento semelhante de pandemia ou que imponha isolamento social, fechamento de fronteiras, dentre outras consequências.

Veja-se, porém, que o destaque dos fatos materiais é absolutamente essencial. Do contrário, o precedente acima considerado conteria uma espécie de regra bastante abstrata: "diante da impossibilidade de pagamento de tributos, prorroga-se o prazo para pagamento". Evidentemente, uma decisão representada apenas por essa fórmula é incompatível com o ordenamento jurídico brasileiro. A ratio decidendi de uma decisão como esta deverá ser marcada pela precisa identificação dos fatos materiais, tal como o seguinte exemplo: "diante da impossibilidade de pagamento de tributos por parte do autor, importador de produtos da República Popular da China, cujo transporte marítimo de mercadorias foi suspenso em decorrência da disseminação da COVID-19, o que impactou diretamente as vendas do requerente, prorroga-se o prazo para pagamento". O ideal, aliás, é que a regra também especifique o tempo pelo qual o prazo foi prorrogado e, se possível, identifique de modo ainda mais claro os aspectos fáticos do caso. Repita-se: a identificação dos fatos materiais é o ponto chave para a questão.

O que não pode ocorrer é a tomada de decisões com fundamentação escassa. No futuro, precedentes pouco específicos poderão se voltar contra os próprios tribunais ao serem invocados para a resolução de casos em condições normais. Ao formar precedentes neste momento, deve-se tomar cuidado para que as decisões pensadas para a pandemia não se tornem a nova posição dos tribunais a respeito de um determinado tema, como se o entendimento anterior estivesse superado.

Há um exemplo recente, da Corte de Apelações da Inglaterra, que embora não relacionado a uma pandemia, auxilia na compreensão do que é aqui sustentando. O caso foi selecionado oir Neil MacCormick para demonstrar seu conceito de universalidade e destacar a importância de se identificar, claramente, os fundamentos essenciais da decisão. Trata-se do caso Re A (children) (conjoined twins) $)^{30}$, que julgou uma situação bastante complexa de gêmeas siamesas. As circunstâncias médicas do caso revelavam que as gêmas Jodie e Mary estavam ligadas pelo inferior do abdome, com uma única coluna cervical, de uma cabeça até a outra, de modo que as duas crianças só poderiam ficar deitadas com as

\footnotetext{
${ }^{29}$ RODRIGUES JR., Otavio Luiz. Dogmática e crítica da jurisprudência (ou da vocação da doutrina em nosso tempo). Revista dos Tribunais, São Paulo, v. 891, p.65-106, jan. 2010.
} 
barrigas para cima ou para baixo. Pior do que isso, apenas os órgãos vitais de uma delas funcionava: era Jodie quem respirava e cujo coração fazia o sangue circular pelas duas. No entanto, o corpo de Jodie não tinha condições de sustentar as duas vidas. Em síntese, para que Jodie sobrevivesse, a vida de Mary teria que acabar.

Os pais das crianças buscaram o Judiciário para obter a autorização da cirurgia, uma vez que os médicos inicialmente se recusaram a realizar o procedimento por receio de que fossem responsabilizados pela morte de Mary. A Corte, ao decidir, tinha dois desafios. Em primeiro lugar, resolver a situação inédita que, por si só, já era complexa. A segunda era formar o precedente sem permitir que as razões da decisão passassem a valer como uma "cláusula geral de eutanásia". Diante dessa tarefa, a Corte de Apelações registrou, pormenorizadamente, os elementos fáticos do caso:

Para evitar que se pense que esta decisão possa se tornar um precedente de dimensões mais amplas, de tal modo que um médico, tendo determinado que seu paciente não pode sobreviver, mate o paciente, é importante reafirmar as circunstâncias únicas para as quais este caso pode ser considerado um precedente. Elas consistem em que seja impossível preservar a vida de $\mathrm{X}$ sem acarretar a morte de $\mathrm{Y}$, que $\mathrm{Y}$, pelo só fato de se manter vivo, vá inevitavelmente ocasionar a morte de $\mathrm{X}$ em um espaço curto de tempo, e que $X$ seja capaz de sobreviver independentemente mas Y seja incapaz de fazê-lo sob quaisquer circunstâncias (incluindo quaisquer formas de intervenção médica). 31

Portanto, ao expor a fundamentação da decisão, é possível registrar os fatos materiais e destacar as circunstâncias específicas da COVID-19 que influenciaram a decisão. Nesta linha, considerando um método bastante relevante de indexação e busca de decisões, é imprescindível que as decisões relacionadas à COVID-19 tenham a pandemia e seus efeitos indicados já na ementa, para evitar futura confusão entre precedentes pandêmicos e os firmados em condições normais.

Nas decisões, o cuidado que os magistrados poderão tomar para diferenciar o entendimento do período da pandemia e o período regular é destacar como fato material, ou como fundamento fático relevante, as imposições da quarentena. Por isso, repita-se, o

30

Reports, v.480, 2001. 31

Elsevier, 2008. p.119.
REINO UNIDO. Court of Appeal. Re A (children) (conjoined twins). Weekly Law

A tradução é de MacCORMICK, Neil. Retórica e o estado de direito. São Paulo: 
ponto central é evitar decisões que não identifiquem, cuidadosamente, as circunstâncias fáticas que contribuíram para a decisão.

\section{Considerações finais}

O presente artigo partiu de duas premissas (a pandemia da COVID-19 e a teoria dos precedentes em vigor no país), e estabeleceu como problema a seguinte questão: se a pandemia alterou as relações jurídicas, como justificar eventual não aplicação de precedente que, em condições normais, seria pertinente ao caso em análise?

Para responder à pergunta formulada, buscou-se a causa do problema e identificouse que a pandemia da COVID-19 torna inúmeros casos fáceis em casos difíceis, na classificação da Teoria do Direito contemporânea. Mais especificamente, os casos relacionados à COVID-19 são difíceis por problemas de prova ou de qualificação, nos termos empregados por Neil MacCormick.

Se os casos são difíceis, este é o primeiro sinal de que não se tem precedentes adequados para os casos surgidos na pandemia. A partir do conceito de fatos materiais, de Arthur Goodhart, constatou-se que entre os casos surgidos em momentos "normais" e no período pandêmico há diferenças fáticas a serem identificadas pelo julgador. Ou seja, não se tem precedentes para os casos da pandemia porque não há casos anteriores que a considerassem na ratio decidendi. Assim, não sendo os casos semelhantes, afasta-se do stare decisis. Os casos surgidos na quarentena deverão ser objeto de distinguishing, É por meio dessa técnica que os advogados fundamentarão a possibilidade de tratamento diferenciado do caso, mesmo com a existência de precedentes apontando para outro sentido.

Ao final, o artigo também sustentou que as decisões proferidas neste período devem tratar pormenorizadamente dos elementos fáticos dos casos a fim de evitar uma utilização deturpada dos precedentes pandêmicos em situações normais. Para tanto, ao expor a fundamentação da decisão, é necessário registrar os fatos materiais e destacar as circunstâncias específicas da COVID-19 que influenciaram a decisão.

\section{REFERÊNCIAS}


ATIENZA, Manuel. As razões do direito. 2.ed. Rio de Janeiro: Forense, 2014.

BARBOZA, Estefânia Maria de Queiroz. Precedentes judiciais e segurança jurídica:

fundamentos e possibilidades para a jurisdição constitucional brasileira. São Paulo: Saraiva, 2014.

BUSTAMANTE. Thomas da Rosa. Teoria do procedente judicial. São Paulo: Noesses, 2012.

CARDOSO, Rômulo. COVID 19: Juiz de Marechal Cândido Rondon determina isolamento de sete pessoas de uma família. Curitiba: Amapar, 2020. Disponível em: <https://bit.ly/2RpDked>. Acesso em: 23 abr. 2020.

CRUZ E TUCCI, José Rogério. Precedente judicial como fonte do direito. São Paulo: Revista dos Tribunais, 2004.

DWORKIN, Ronald. Is Law a system of rules? In: The Philosophy of Law. Oxford: Oxford University Press, 1977. p. 14-46.

DWORKIN, Ronald. Taking Rights Seriously. Cambridge: Harvard University Press, 1977.

EISENBERG, Melvin Aron. The nature of the common law. Cambridge: Harvard University Press, 1988.

GOODHART, Arthur L. Determining the ratio decidendi of a case. Yale Law Journal, Yale, v.40, n.2, p.161-183, dez. 1930.

HART, Herbert L. A. The concept of Law. 3.ed. Oxford: Oxford University Press, 2012.

KOZICKI, Katya; PUGLIESE, William S. Direito, Estado e Razão Prática: a teoria do direito de Neil MacCormick. In: TORRANO, Bruno; OMMATI, José Emílio Medauar (Org.). O positivismo jurídico no século XXI. Rio de Janeiro: Lumen Juris, 2018. p.145-181.

MacCORMICK, Neil. Argumentação jurídica e teoria do direito. São Paulo: Martins Fontes, 2006.

MacCORMICK, Neil. Retórica e o estado de direito. São Paulo: Elsevier, 2008.

MACEDO JR., Ronaldo Porto. Do xadrez à cortesia: Dworkin e a teoria do direito contemporânea. São Paulo: Saraiva, 2013.. 
MARINONI, Luiz Guilherme. Precedentes obrigatórios. São Paulo: Revista dos Tribunais, 2010.

MERRYMAN, John Henry; PÉREZ-PERDOMO, Rogelio. A tradição da Civil Law: uma introdução aos sistemas jurídicos da Europa e da América Latina. Tradução de Cássio Casagrande. Porto Alegre: Sergio Antonio Fabris, 2009.

MITIDIERO, Daniel. Precedentes: da persuasão à vinculação. São Paulo: Revista dos Tribunais, 2016.

REINO UNIDO. Court of Appeal. Re A (children) (conjoined twins). Weekly Law Reports, v.480, 2001.

RODRIGUES JR., Otavio Luiz. Dogmática e crítica da jurisprudência (ou da vocação da doutrina em nosso tempo). Revista dos Tribunais, São Paulo, v. 891, p.65-106, jan. 2010 .

SERBENA, Cesar Antonio. Teoria da derrotabilidade: pressupostos teóricos e aplicações. Curitiba: Juruá, 2012.

SHANNON, Bradley Scott. The Retroactive and Prospective Application of Judicial Decisions. Harvard Journal of Law \& Public Policy, Cambridge, v.26, p.812-876, 2003.

VASCONCELLOS, Fernando Andreoni. Hermenêutica jurídica e derrotabilidade. Curitiba: Juruá, 2010.

XAVIER, Marília Pedroso. Como evitar oportunismos nas revisionais de alimentos na pandemia. Consultor Jurídico, São Paulo, 2020. Disponível em: $<$ https://www.conjur.com.br/2020-abr-15/direito-civil-atual-evitar-oportunismosrevisionais-alimentos>. Acesso em: 17 de maio de 2020. 